\title{
Comment on: Failure to rescue in patients with distal pancreatectomy: a nationwide analysis of 10,632 patients
}

\author{
Ugo Marchese $^{1 \wedge}$, David Fuks ${ }^{1}$, Stephanie Truant ${ }^{2}$, Mehdi El Amrani \\ ${ }^{1}$ Department of Digestive, Hepatobiliary and Endocrine Surgery, Paris University, Cochin Hospital, AP-HP, 75014 Paris, France; ${ }^{2}$ Department of \\ Digestive Surgery and Transplantation, Lille University, CHRU de Lille, Lille, France \\ Correspondence to: Ugo Marchese. Department of Digestive, Hepatobiliary and Endocrine Surgery, Paris University, Cochin Hospital, AP-HP Centre, \\ 27 rue du Faubourg Saint-Jacques, 75014 Paris, France. Email: ugo.marchese@aphp.fr. \\ Comment on: Lequeu JB, Cottenet J, Facy O, et al. Failure to rescue in patients with distal pancreatectomy: a nationwide analysis of 10,632 patients. \\ HPB (Oxford) 2021. [Epub ahead of print]. doi: 10.1016/j.hpb.2021.02.002.
}

Submitted Mar 10, 2021. Accepted for publication Mar 20, 2021.

doi: 10.21037/hbsn-21-105

View this article at: http://dx.doi.org/10.21037/hbsn-21-105

We read with great interest the article recently published by Lequeu et al. (1) based on the French national administrative prospective database for hospital care (PMSI: Programme de Médicalisation des Systèmes d'Information) containing all discharge reports from both private and public hospitals in France. This series aimed at evaluating the influence of hospital volume on failure to rescue after distal pancreatectomy (DP) with or without splenectomy by open and minimally invasive surgery. Collecting number of deaths among patients who experienced major postoperative complication, failure to rescue (FTR) represents the inability for a center to manage these complications and to avoid postoperative deaths. Indeed, FTR appears to be a relevant indicator of quality of care after surgical procedures related to postoperative morbidity and its management.

Among 10,632 patients who underwent DP between 2009 and 2018, 5,048 (47.5\%) were operated in 602 (95.4\%) low volume centers and 5,584 (52.5\%) in 29 (4.6\%) high volume centers. In this article, the cutoff between high and low volume centers was 20 pancreatectomies per year. These proportions were constant in the 3 periods of observation (2009-2011, 2012-2014 and 2015-2018). Patients treated in low volume centers were older (64.3 vs. 61.7 years, $\mathrm{P}<0.001$ ), with a higher Charlson comorbidity index (ChCI, using the validated Charlson comorbidity score) (CCI 0-2: $59 \%$ vs. $63 \%$, CCI $\geq 4: 26.3 \%$ vs. $22.1 \%$, $\mathrm{P}<0.001)$ and more frequently treated for a malignancy
(69.2\% vs. $65.8 \%, \mathrm{P}<0.001)$ than patients treated in high volume centers. Overall FTR occurred in $11.2 \%$ of patients and was significantly reduced in high volume centers compared to low volume centers (10.2\% vs. $12.5 \%$, $\mathrm{P}=0.047)$. Overall, postoperative mortality (POM) remained stable over time (3.9\%) however FTR rates decreased (13.8\% between 2009-2011 vs. 10.2\% between 2015-2018, $\mathrm{P}=0.039)$. In multivariate analysis, surgery in a high-volume center was a protective factor for mortality $(\mathrm{OR}=0.570$, 95\% CI: $0.505-0.643, \mathrm{P}<0.001)$ and also for FTR (OR $=0.550,95 \%$ CI: $0.486-0.630, \mathrm{P}<0.001)$. Interestingly, male patients with high ChCI undergoing open DP for malignancy represented the subgroup of patients with higher risk of FTR. There were a linear increased in FTR and in POM with age and ChCI. Based on these results, the authors concluded that hospital volume has a positive impact on FTR in DP.

Pancreatic surgery is associated with a high postoperative morbidity and may lead to patient death if the expertise of the multidisciplinary teams, the availability of intensive care unit and emergency interventional procedures fail to rescue the patient that experiences a major complication. In their series, Lequeu et al. confirmed that half of DP was performed in 29 high-volume centers and the other half in more than 600 low-volume centers corresponding to an average of $1.1 \mathrm{DP} /$ year/center during this 10-years study. The same proportions were observed in the three different

\footnotetext{
$\wedge$ ORCID: 0000-0002-8647-7584.
} 
periods of observation which confirm that DP is still considered as a non-challenging procedure for the majority of the French surgical teams.

In the meantime, Roussel et al. recently published a series of DP based on the same national French database (2). The aim of this series was to define high volume centers and identify a volume cut off before evaluating its impact on postoperative course. On the other hand, Lequeu et al. deliberately used the cut off of 20 pancreatectomy/year, as previously defined by El Amrani et al. and which was calculated for all type of pancreatectomies (3). Curiously, Roussel et al. did not investigate FTR rates and failed to identify any correlation between hospital volume and POM after DP. The authors concluded that the period of inclusion was too short considering the low incidence of POM and this fact could underestimate the impact of hospital volume. With a longer study period, Lequeu et al. showed for the first time an impact of hospital volume on both POM and FTR rates.

Indeed, variations in POM between hospitals after pancreatoduodenectomy can be explained by differences in FTR, rather than the incidence of major complications (4). In this setting, FTR is directly correlated with hospital volume which suggests that these procedures should be performed preferentially in high-volume hospitals. Northern European countries started more than five years ago a pancreatic surgery centralization program and results show that this centralization contributes to improve both postoperative outcomes (5) and oncological results (6). Despite these results, pancreatic surgery remains a widespread surgical procedure in France.

This nationwide series reported a relative high mortality (3.9\%) and overall major morbidity (29.6\%) compared to rates usually reported by high volume centers in current literature (7). Interestingly, the authors also identified that incidence of major complications increased during the most recent study period without any decrease in POM rates. This surprising observation may be explained by a more exhaustive data collection but also by a less stringent selection of patients. This result suggests that progressive centralization in France is insufficient.

Although patients managed in high-volume centers are usually younger, with lower comorbidity index score and a lower rate of malignant disease (8), this article emphasizes that centralization should focus at least in the first instance, on high-risk patients identified as elderly male with high ChCI treated for malignancy.

In conclusion, this study is the first to identify a direct correlation between hospital volume and FTR after distal pancreatectomy even if POM is lower after this procedure. Moreover, authors provide an interesting concept for optimized centralization that may lead to a global improvement of pancreatic surgery's results in France without excessive movement of patients and supplementary cost for health care authorities.

\section{Acknowledgments}

Funding: None.

\section{Footnote}

Provenance and Peer Review: This article was commissioned by the editorial office of Hepatobiliary Surgery and Nutrition. The article did not undergo external peer review.

Conflicts of Interest: All authors have completed the ICMJE uniform disclosure form (available at https://hbsn. amegroups.com/article/view/10.21037/hbsn-21-105/coif). The authors have no conflicts of interest to declare.

Ethical Statement: The authors are accountable for all aspects of the work in ensuring that questions related to the accuracy or integrity of any part of the work are appropriately investigated and resolved.

Open Access Statement: This is an Open Access article distributed in accordance with the Creative Commons Attribution-NonCommercial-NoDerivs 4.0 International License (CC BY-NC-ND 4.0), which permits the noncommercial replication and distribution of the article with the strict proviso that no changes or edits are made and the original work is properly cited (including links to both the formal publication through the relevant DOI and the license). See: https://creativecommons.org/licenses/by-nc-nd/4.0/.

\section{References}

1. Lequeu JB, Cottenet J, Facy O, et al. Failure to rescue in patients with distal pancreatectomy: a nationwide analysis of 10,632 patients. HPB (Oxford) 2021. [Epub ahead of print]. doi: 10.1016/j.hpb.2021.02.002.

2. Roussel E, Clément G, Lenne $\mathrm{X}$, et al. Is Centralization Needed for Patients Undergoing Distal Pancreatectomy?: A Nationwide Study of 3314 Patients. Pancreas 2019;48:1188-94. 
3. El Amrani M, Clement G, Lenne X, et al. Failureto-rescue in Patients Undergoing Pancreatectomy: Is Hospital Volume a Standard for Quality Improvement Programs? Nationwide Analysis of 12,333 Patients. Ann Surg. nov 2018;268:799-807.

4. van Rijssen LB, Zwart MJ, van Dieren S, et al. Variation in hospital mortality after pancreatoduodenectomy is related to failure to rescue rather than major complications: a nationwide audit. HPB (Oxford) 2018;20:759-67.

5. Onete VG, Besselink MG, Salsbach CM, et al. Impact of centralization of pancreatoduodenectomy on reported

Cite this article as: Marchese U, Fuks D, Truant S, El Amrani M. Comment on: Failure to rescue in patients with distal pancreatectomy: a nationwide analysis of 10,632 patients. HepatoBiliary Surg Nutr 2021;10(2):229-231. doi: 10.21037/ hbsn-21-105 radical resections rates in a nationwide pathology database. HPB (Oxford) 2015;17:736-42.

6. Ahola R, Siiki A, Vasama K, et al. Effect of centralization on long-term survival after resection of pancreatic ductal adenocarcinoma. Br J Surg 2017;104:1532-8.

7. Jiang L, Ning D, Chen XP. Improvement in distal pancreatectomy for tumors in the body and tail of the pancreas. World J Surg Oncol 2021;19:49.

8. El Amrani M, Clément G, Lenne X, et al. Should all pancreatic surgery be centralized regardless of patients' comorbidity? HPB (Oxford) 2020;22:1057-66. 